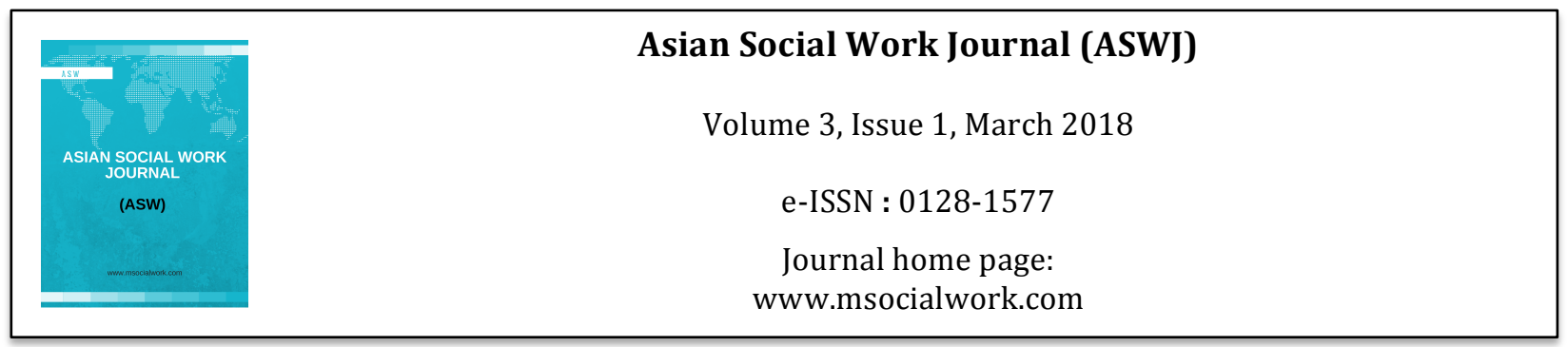

\title{
Emotional Intelligence and Religious Orientation among Volunteers and Non- Volunteers in Malaysia
}

\author{
Nurul Hudani Md Nawi ${ }^{1}$, Puteri Hayati Megat Ahmad ${ }^{1}$ \\ 1Fakulti Psikologi dan Pendidikan, Universiti Malaysia Sabah (UMS) \\ Corrrespondence: Nurul Hudani Md Nawi (nurul@ums.edu.my)
}

\begin{abstract}
An investigation into the characteristics of volunteers is important to understand why people volunteer. From an applied point of view, these understanding can help to better manage and retain the volunteers in voluntary organizations. The present study compared volunteers and non-volunteers in Sabah using a cross-sectional survey method. Questionnaire packet consisting of measures of religious orientation, and emotional intelligence were self-administered by the respondents. One hundred and sixty eight of them were volunteers and one hundred and eight were non-volunteers. Findings showed that there was no significant difference between volunteers and non-volunteers in term of emotional intelligence $(\mathrm{t}=-$ $0.13 \mathrm{p}>0.05)$. However, both aspects in religious orientation i.e. Intrinsic Religious Orientation $(\mathrm{t}=3.96$, $\mathrm{p}<0.05)$ and Extrinsic-Personal Orientation $(\mathrm{t}=3.74, \mathrm{p}<0.05)$ showed that there were significant differences between volunteers and non-volunteers. Moreover, the result showed that volunteers have low mean score for both aspect in religious orientation namely Intrinsic Orientation (mean=19.19, SD: 2.32) and Extrinsic-Personal Orientation (mean=7.83, SD: 1.68) compared to non-volunteers (mean=20.29, SD: 2.06$)$ and (mean=8.44, SD: 1.01). It showed that, mostly volunteers reported less personal gain from embracing religion. The results was also indicated that volunteers can be distinguished from non-volunteers in term of religious orientation. On a practical note, the assessment of EI in voluntary workers could possibly assist in enhancing the human resource management plan especially in training development. Excellent management of this unique group of workers can lead to the success of voluntary organizations in delivering huge benefits to the society.
\end{abstract}

Key words: emotional intelligence, religious orientation, volunteerism, voluntary organizations

\section{Introduction}

A proper and structured management of voluntary workers in organizations is vital to ensure the effectiveness of these services to the community. In fact, volunteers should be protected against too much physical and emotional burden. Therefore, the tolerance towards the emotional aspects of volunteer work, in turn, can be influenced by a person's characteristics such as emotional intelligence (EI).

The volunteers in an organized group, like other profit oriented employees, require appropriate management. As of the beginning of the $21^{\text {st }}$ century, volunteer program management is only less than 40 years old. The need for good management comes from the fact that volunteering can be cost- 
effective, but not cost-free. Effective management of people in voluntary organizations can help minimize cost, and ensuring continuity of service.

People participate in volunteer work in various ways. By pooling available resources, people can do much more than they can do alone. That is why there is a need to mobilize individuals in an organized manner. To manage volunteers professionally, much like the human resource department in many organizations, the volunteer organization needs professional input. In Malaysia, there are organisations that recruit volunteers. The platform of these organizations may include political groups, animal welfare organizations, charitable organizations, health-related services, advocacy groups, or sports organizations. The existence of many volunteer organizations, however does not necessarily mean they all are functioning effectively. There may be organizations that exist in name only because of lack of volunteer staff.

\section{Volunteerism}

Volunteerism refers to a "set of activities in which people engage, usually without pay, on behalf of others in need" (Wilson \& Janowski, 1995). Other related words and concepts include pro-social behaviour, helping behaviour, and organizational citizenship behaviour. Another definition of voluntary activity is "any activity intended to help others that is provided without obligation for which the volunteer does not receive pay or other material compensation. Voluntary behavior is a type of prosocial behavior. It can either be spontaneous (as in an emergency situation) or non-spontaneous (as in organized or planned). However, volunteering is not at the same level of spontaneous helping behavior or other simple forms of civic engagement (Uslaner, 2002). Uslaner argued that giving to charity requires material resources. But, volunteering requires moral resources. This becomes the important tenet for discussing the relationship between volunteering and religion.

There are several functions served by voluntary activities (Clary, Snyder, Ridge, Copeland, Stukas, Haugen, \& Miene,1998). These include the following:

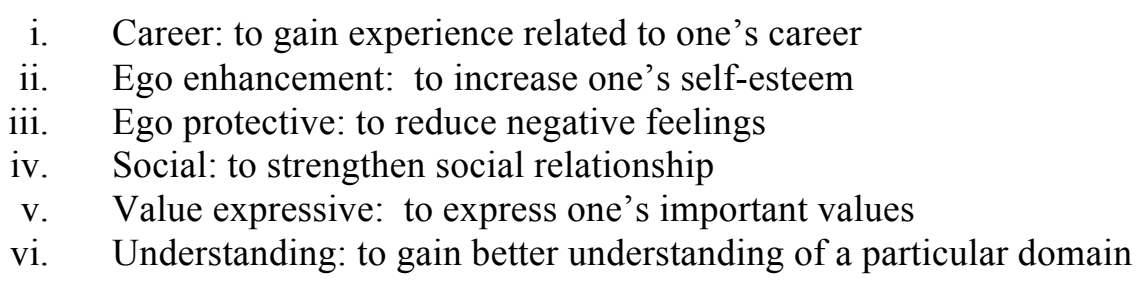

The works done by organized voluntary groups are beneficial. They help to create a stable and cohesive society, add value to the services that government provides and promotes good health and emotional well-being. In this study, volunteerism is defined as the involvement in activity that benefits others without necessarily benefiting oneself. Operationally, volunteerism is conceptualized as belonging to at least one formal voluntary organization. The length of membership and level of involvement in the organization are not considered.

\section{Volunteerism and Religiosity}

Religions, revealed or otherwise, have teachings that lead to a positive and constructive life. According to Maltby (2002), a common factor in all major religion is the creation of harmony in life. Indeed, in many religions, there are teachings to treat others as one would like to be treated.

However, in reality many instances of violence, cruelty, and bloodshed are linked to religious people. Even though there is opposition to the emphasis on the relationship between religion and violence, we cannot escape from admitting that religious consideration plays a significant role in many world conflicts. Amid the social, political, economic, and traditional cultural, how strong is the influence of religion in creating global peace? Can religious teachings shape its followers behaviour? 
Within this context, we can discuss the relationship between religiosity and pro-social behaviour such as voluntary activities. There are different conceptualizations of religiosity. Among the more well researched and established measure of religiosity is the intrinsic-extrinsic orientation which was put forward by Allport and Ross (Gorsuch and McPherson, 1989). In a study that is based on Allport and Ross's measure, Hansen, Vandenberg and Patterson (1995) found that persons with intrinsic religious orientation prefer non-spontaneous (as in organized or planned) helping opportunities. They reported more hours involved in volunteer activity in the past year compared with people with quest orientation. Those with intrinsic orientation also commit themselves less to spontaneous helping opportunities.

In another experiment, devout intrinsic religion is associated with antipathy towards value violators (Batson, Flyod, Meyer, \& Winner, 1999). They are less likely to donate money to help people who violate religious values. Taken together, these seem to suggest that people with intrinsic religion will be more likely to participate in planned voluntary organizations that do not violate their religious values.

Using other measures of religiosity, researchers have also attempted to investigate the relationship between religiosity and volunteer work. Religiosity was found to be the strongest influence on local volunteer activity among churchgoing Protestants (Park \& Smith, 2000). Other measures like religious identity, religious socialization and background characteristics have lesser influence. In a locally done study, attitude towards volunteerism did not differ by strength of religious value adherence as measured by a single item. After reviewing research on voluntary action and faith, Lukka and Locke (2000) concluded that researchers can not readily generalize research findings from faith-based volunteering on research done in the US. In the same manner, the authors felt it was imperative for further studies be conducted among Malaysians so as to better understand the link and difference between religiosity, emotional intelligence and voluntary actions.

In this study, religious orientation refers to how a person thinks of and behaves according to his or her religion. It is divided into intrinsic (living a religion for the sake of religion) and extrinsic (living a religion for material, social, and spiritual gains). The concept of religious orientation is different from attitude towards religion which refers to a person's positive or negative evaluation of the religion. Operationally, religious orientation is defined by a person's score on the Age Universal I-E Scale.

\section{Emotional Intelligence}

Salovey and Mayer (1990) defined emotional intelligence as three adaptive abilities namely the ability (1) to appraise and express emotion, (2) to regulate emotions, and (3) to utilize emotions in solving problems. The first two abilities apply to oneself and others. Another definition contains an elaboration of the components of appraisal and utilizing emotion. Emotional intelligence is said to refer to "an ability to recognize the meanings of emotions and their relationships, and to reason and problem-solve on the basis of them" (Mayer, Caruso \& Salovey, 2000, p. 267). Their model of emotional intelligence involves four branches namely 'reflectively regulating emotions', 'understanding emotions', 'assimilating emotion in thought' and 'perceiving and expressing emotion'.

Other models also offer different numbers of the EI component. The model by Dulewicz and Higgs (1999) has seven components (self-awareness, emotional resilience, motivation, interpersonal sensitivity, influence, intuitiveness, and conscientiousness and integrity). Meanwhile, Bar-On's (1997) definition of emotional intelligence includes non-cognitive capabilities. Bar-On's Emotional Quotient Inventory consists of five composite factors (intra-personal, inter-personal, adaptability, stress management, and general mood) and 15 sub-scales.

Daniel Goleman helped to popularize the term emotional intelligence. According to Goleman (1995 \& 1998), emotional intelligence is an important factor in determining personal success as a student, teacher, parent, manager, and leader. However, hard evidence on the link between emotional intelligence and leadership is sparse (Higgs \& Aitken, 2003; Palmer, Walls, Burgess \& Stough, 2001). 
This paucity can be attributed to, among other, the differing ways of conceptualizing emotional intelligence. Petrides and Furnham (2000) listed three main models namely the hierarchical model,ability model (cognitive) and mixed models (personality variables plus cognitive ability). It is in the same publication that Petrides and Furnham distinguish trait EI from information-processing EI. Therefore, we can measure EI as a trait or as an information-processing skill or a combination of both.

Researchers have reported studies investigating relationship between emotional intelligence and other variables such as problem behaviour among Malaysian secondary school students (Liau, Liau, Teoh, \& Liau, 2003), smoking behaviour among adolescent (Trinidad, \& Johnson, 2002; Trinidad, Unger, Chou, \& Johnson, 2004), academic achievement, cognitive ability, and personality (O'Connor, \& Little, 2003), stress and mental health (Ciarrochi, Deane, \& Anderson, 2002), and emotional well-being (Schutte, Malouff, Simunek, McKenly, \& Hollander, 2002).

Noting the "need for a brief and validated measure of EI based on a cohesive and comprehensive model of EI" (p. 169), Schutte, Malouff, Hall, Haggerty, Cooper, Golden and Dornheim (1998) developed the self-report EI scale. The 33-item trait EI scale is based on the model of EI developed by Salovey and Mayer (1990). It was meant "to provide a solid foundation for a measure of individuals' current level of EI" (Schutte et al., 1998, p. 169). In their validation study, Schutte et al. found that their measure of EI correlates with other relevant measures of emotional intelligence. Modifications (changes in some items, addition of new items, and inclusion of item reversals) to the original scales did not improve the scale's internal reliability (Austin, Saklofske, Huang \& McKenney, 2004). This study indirectly support the idea that response to the scale is not influenced by social desirability effect (which the Lie scale of the EPQ measures).

For the current study, the authors retained the original items for translation into the Malay Language. The translation work was done to suit the scale for the student participants and more importantly, for future use in the general local population. Therefore, the definition of emotional intelligence is the same as adopted by Schutte et al_(1988) The construct is operationally defined as the score on the EI scale developed by Schutte et al (1998).

\section{Religious Orientation}

Religious orientation refers to how a person thinks of and behaves according to his or her religion. In this study, the orientation is divided into intrinsic (living a religion for the sake of religion) and extrinsic (living a religion for material, social, and spiritual gains). The concept of religious orientation is different from attitude towards religion which refers to a person's positive or negative evaluation of the religion. Operationally, religious orientation is defined by a person's score on the Age Universal IE Scale.

\section{Study Objectives}

The objectives of this study are as follow:

i. To investigate the mean difference of religious orientation (intrinsic, extrinsic personal and extrinsic social) between volunteers and non-volunteers

ii. To investigate the mean difference of emotional intelligence between volunteers and nonvolunteers

\section{Research Design}

The authors opted for a cross-sectional design due to time constraints. The phenomena under scrutiny is observed among people of different age groups at the same time. Only the survey method was used 
due to the fact that this study is a fundamental type of study. It is meant to be the foundation for further studies.

\section{Instruments}

The questionnaire pack comprises sections that measures demographic information, religious orientation and emotional intelligence. All parts of the questionnaire have both English and Malay Language versions. Back translation method was used to ensure the accuracy of the translation.

\section{Demographic Items}

The respondents were required to answer questions about their age, sex, race, religion, marital status and frequency of involvement in planned volunteer work.

\section{Religious Orientation Scale (Age Universal I-E Scale)}

Section A consists of Age Universal I-E Scale using 14 items derived by Gorsuch and McPherson (1989). The answer format was three point scale where $1=$ No, $2=$ Not Sure, and $3=$ Yes. There are three subscales namely Intrinsic (8 items), Extrinsic-Personal ( $\left.E_{\mathrm{P}}\right)$ (3 items), and Extrinsic-Social ( $\left.\mathrm{E}_{\mathrm{S}}\right)$ (3 items).

The origin of this scale can be traced to Allport and Ross (1967). Changes have been made by considering suggestions from Maltby and Lewis (1996) and Maltby (2002). These changes make the scale suitable for people of different ages and also to non-religious people. In addition, to make the scale suitable for non-Christian respondents, the word "church" in items 2, 11, 13 was changed to "tempat ibadat" (place or worship).

\section{Emotional Intelligence Scale}

This part is the 33-item emotional intelligence scale (Schutte et al., 1998) that has been translated into Malay Language by the authors. The scale uses a 5-point scale where "1" represents "strongly disagree" and " 5 " represents "strongly agree". Thus, the higher the total score, the higher the EI. The original authors reported that the scale is unidimensional, reflecting a general EI factor (Schutte et al., 1998). However, in an exploratory factor analysis using varimax-rotated solution, Petrides and Furnham (2000) came out with four factors in which they labeled 'optimism/mood regulation', 'appraisal of emotion', 'social skills', and 'utilization of emotions.' With a more complex analysis, Saklofske, Austin and Minski (2003) suggested a hierarchical factor structure with a super-ordinate factor and four lower-level factors. They suggested that the scale could be analyzed according to the total score and also according to the four factors. The scale's internal consistency range from .90 to .87 , and its test-retest reliability was reported at 0.78 (Schutte et al., 1998).

\section{Instrument Translation and Cross-Cultural Adaptation}

Both instruments were initially translated into Malay (forward translation) by two bilingual translators who were Malay native speakers working independently of each other. The two Malay versions were revised by researchers and reconciled into one Malay version. This was then back-translated into English by a native English speaker who has a good command of the Malay language. Following this, further discussions and modifications were carried out by the researchers based on the forward and back versions before generating the final Malay instruments. The Emotional Intelligence Scale, and Religious Orientation Scale were then administered to a small group of respondent $(n=22)$ with the aim of testing its psychometric properties as well as to suit its application in the Malaysian culture. They were found to be reliable. 


\section{Study Procedure}

Before the study began, ethical approval was first obtained from the organization involved. Upon this official clearance, initial verbal contact was then made to the selected organization to explain the intention of the study, the period involved and what was required from the respondents. This process was later followed by an official letter of application. Upon receiving the official approval from each organization, a further verbal discussion through the telephone was made to the appointed coordinator(s). The aim was to arrange the date and time of the day(s) suitable for meeting the respondents.

On the agreed meeting day, the researchers and assistants met, explained and invited potential respondents to participate in the study. An information sheet was given to enhance their understanding on the nature of the study as well as clarifying the particulars needed, the instrument used and what was required from them. Once agreed, participants signed a written consent form and proceeded to complete the set of instruments in this order: Personal Information Form, Emotional Intelligence Scale, and Religious Orientation Scale. Once completed, they were thanked for their participation.

\section{Data Analysis}

The data were analysed using SPSS for Windows 9.00. Statistical analysis like frequency, mean, standard deviation, correlation and independent sample $t$-test were used. However, different variables were analysed based on different $N$ size, depending on complete answers given for each variable. Therefore, not all variables are based on 276 respondents.

\section{Measures Reliability}

Internal consistency is used as the reliability estimate for all scales. For this purpose, $\alpha$-Cronbach alpha was calculated and presented in Table 1 . The measures were found to vary widely in their internal reliability, with Cronbach alpha ranging from .60 to .77. (Refer Table 1)

Table 1: Internal Reliability ( $\alpha$-Cronbach) of the Scales

\begin{tabular}{lll}
\hline Measures & $N$ & $\alpha$-Cronbach \\
\hline Age Universal I-E Scale & & \\
$\quad$ Intrinsic & 267 & .2868 \\
Extrinsic-Personal & 271 & .6086 \\
Extrinsic-Social & 272 & .5611 \\
Emotional Intelligence Scale & 266 & .7658 \\
\hline
\end{tabular}

\section{Respondents}

There were 276 respondents who completed the study. Respondents were individuals who resides in several selected locations in Sabah namely Kota Kinabalu, Tawau, Sandakan, and Keningau. For volunteers, the individuals are identified by their involvement in a formally recognized volunteer organizations. For non-volunteers, the respondents are chosen from the public. The method of sampling for both groups was convenient sampling. 


\section{Descriptive Statistics Result}

The descriptive statistics are presented to provide background information on the respondents and scales used. The analysis for the scales was done based on all respondents. However, the information about the respondents themselves was analyzed by groups. (Refer Table 2). Table 2 presents the number and percentages of the volunteers and non-volunteers who are males and females. Overall, there are more female respondents. There are slightly more females (in terms of percentage) in the nonvolunteer group.

Table 2: The Number and Percentage of Respondent by Sex

\begin{tabular}{lcccccc}
\hline Sex & \multicolumn{2}{c}{ Volunteers } & \multicolumn{2}{c}{ Non-volunteers } & \multicolumn{2}{c}{ All } \\
\hline & $N$ & $\%$ & $N$ & $\%$ & $N$ & $\%$ \\
Males & 73 & 43.5 & 43 & 39.8 & 116 & 42.0 \\
Females & 93 & 55.4 & 65 & 60.2 & 158 & 57.2 \\
Missing value & 2 & 1.2 & 0 & 0.0 & 2 & .7 \\
\hline Total & 168 & 100.0 & 108 & 100.0 & 276 & 100 \\
\hline
\end{tabular}

From Table 3, we can see that the largest racial group among the volunteers is Chinese, while for the non-volunteers it is the Kadazan Dusun. There were no Indians in the non-volunteers group compared to seven in the volunteers group. The Chinese are highly represented in the volunteer group, but is underrepresented in the non-volunteer group. The reverse representation is observed for the Malay and Bajau ethic groups. These asymmetries make it hard to compare the two groups based on race.

Table 3: The Number and Percentage of Respondent by Race

\begin{tabular}{lcccccc}
\hline Race & \multicolumn{2}{c}{ Volunteers } & \multicolumn{2}{c}{ Non-volunteers } & \multicolumn{2}{c}{ All } \\
\hline Malay & $N$ & $\%$ & $N$ & $\%$ & $N$ & $\%$ \\
Chinese & 10 & 6.0 & 34 & 31.8 & 44 & 15.9 \\
Indian & 83 & 49.4 & 1 & .6 & 84 & 30.4 \\
Kadazandusun & 7 & 4.2 & 0 & 0.0 & 7 & 2.5 \\
Bajau & 41 & 24.4 & 39 & 36.1 & 80 & 29.0 \\
Melayu Brunei & 1 & 0.6 & 12 & 11.1 & 13 & 4.7 \\
Others & 5 & 3.0 & 9 & 8.3 & 14 & 5.1 \\
\hline Total & 22 & 13.1 & 12 & 11.1 & 34 & 12.3 \\
\hline
\end{tabular}

The majority of the volunteers are Christian while the majority of the non-volunteers are Muslim (see Table 4). Again, asymmetry between the groups is observed. The asymmetry is even more noticeable than for race in Table 3 .

Table 4: The Number and Percentage of Respondent by Religion

\begin{tabular}{|c|c|c|c|c|c|c|}
\hline \multirow[t]{2}{*}{ Religion } & \multicolumn{2}{|c|}{ Volunteers } & \multicolumn{2}{|c|}{ Non-volunteers } & \multicolumn{2}{|c|}{ All } \\
\hline & $N$ & $\%$ & $N$ & $\%$ & $N$ & $\%$ \\
\hline Islam & 16 & 9.5 & 77 & 71.3 & 93 & 33.7 \\
\hline Buddhism & 41 & 24.4 & 0 & 0.0 & 41 & 14.9 \\
\hline Hinduism & 4 & 2.4 & 0 & 0.0 & 4 & 1.4 \\
\hline Christianity & 104 & 61.9 & 30 & 27.8 & 134 & 48.6 \\
\hline Others & 2 & 1.2 & 1 & .9 & 3 & 1.1 \\
\hline Missing & 1 & .6 & 0 & 0.0 & 1 & .4 \\
\hline Total & 168 & 100.0 & 108 & 100.0 & 276 & 100.0 \\
\hline
\end{tabular}


As evident from Table 5, a majority of the volunteers and non-volunteers are married. However, there is a higher proportion of singles in the volunteers group compared to non-volunteers. Among the nonvolunteers, the lower proportion of singles is matched with a higher proportion of widowers, divorcees, or single mothers.

Table 5: The Number and Percentage of Respondent by Marital Status

\begin{tabular}{lcccccc}
\hline Marital status & \multicolumn{2}{c}{ Volunteers } & \multicolumn{2}{c}{ Non-volunteers } & \multicolumn{2}{c}{ All } \\
\hline & $N$ & $\%$ & $N$ & $\%$ & $N$ & $\%$ \\
\hline Married & 93 & 55.4 & 68 & 63.0 & 161 & 58.3 \\
Single & 74 & 44.0 & 29 & 26.9 & 103 & 37.3 \\
Widowed / Divorced / & 1 & .6 & 11 & 10.2 & 12 & 4.3 \\
Single mother & & & & & & \\
\hline Total & 168 & 100.0 & 108 & 100.0 & 276 & 100.0 \\
\hline
\end{tabular}

Table 6 revealed some surprising results. Among the volunteers, a majority were involved at least once a week. What is surprising is that $18.5 \%$ reported that they never participated in any planned voluntary activities despite belonging to a voluntary organization. Another unexpected outcome is observed in the non-volunteer group where one respondent reported having participated at least once a month. Data for this person was then transferred to the volunteers group.

Table 6 : The Number and Percentage of Respondent by Frequency of Participation in Voluntary Activities

\begin{tabular}{lcccccc}
\hline Frequency of & \multicolumn{2}{c}{ Volunteers } & \multicolumn{2}{c}{ Non-volunteers } & \multicolumn{2}{c}{ All } \\
\cline { 2 - 7 } participation & $\mathrm{N}$ & $\%$ & $\mathrm{~N}$ & $\%$ & $\mathrm{~N}$ & $\%$ \\
\hline At least once a week & 57 & 33.9 & 0 & 0 & 57 & 20.7 \\
At least once a month & 45 & 26.8 & 1 & .9 & 46 & 16.7 \\
At least once a year & 33 & 19.6 & 0 & 0 & 33 & 12.0 \\
Never & 31 & 18.5 & 106 & 98.1 & 137 & 49.6 \\
Missing & 2 & 1.2 & 1 & .9 & 3 & 1.1 \\
\hline Total & 168 & 100.0 & 107 & 100 & 276 & 100.0 \\
\hline
\end{tabular}

Besides, both groups are also moderately high in their level of emotional intelligence, scoring about $77 \%$ of the maximum score. Moreover, the standard deviation of scores in each group is about the same. This indicates that the emotional intelligence scores for both groups could have come from the same distribution.

The scores for Extrinsic-Personal scale are high. Many respondents reported the personal benefits of religion. However, the variability of scores is greater for volunteers. The respondents reported a lower level of Extrinsic-Social orientation, scoring at about the midpoint of the possible score. Unlike with Extrinsic-Personal, the variability of scores is about the same for both groups. For the Intrinsic orientation, high scores are observed. The respondents endorsed many items that measure the role of religion in finding meanings and purpose in life (i.e. adopting a religion for its own sake).

As for religious orientation, it was found that volunteers did not have a higher intrinsic religiosity score than non-volunteers. Therefore, this hypothesis is rejected. Whereas (volunteers and non-volunteers have similar Extrinsic-Social religiosity score) is accepted. The hypothesis about (volunteers and nonvolunteers have similar Extrinsic-Personal religiosity scores) is rejected. There was a significant difference between the two groups with volunteers reporting a lower score than non-volunteer.

Table 7 indicates that there was no significant difference between volunteers and non-volunteers in term of emotional intelligence $(\mathrm{t}=-0.13 \mathrm{p}>0.05)$. Both aspects in religious orientation i.e., Intrinsic 
Religious Orientation $(\mathrm{t}=3.96, \mathrm{p}<0.05)$ and Extrinsic-Personal Orientation $(\mathrm{t}=3.74, \mathrm{p}<0.05)$ showed that there were significant differences between volunteers and non-volunteers.

Table 7 : Independent Samples (Volunteers vs Non-volunteers) t-test Results for Scales

\begin{tabular}{lrrr}
\hline Scales & $t$ & $d f$ & $P$ \\
\hline EI & -0.136 & 264 & .892 \\
Extrinsic $_{\mathrm{P}}$ & -3.741 & 267.375 & .000 \\
Extrinsic $_{\mathrm{S}}$ & -0.666 & 270 & .506 \\
\hline
\end{tabular}

\section{Discussion}

As for emotional intelligence, no difference was observed between volunteers and non-volunteers. It shows that both group felt justifiably good about their emotions such as having the ability to recognize emotion in their relationship with others and able to leave positive effect on others. This is consistent with the empathic joy hypothesis for pro-social behaviour. However this result is inconsistent with the study by Salovey and Meyer (1990) show that emotional intelligence is a critical component of successful outcomes in organization management especially for the volunteer workers. This support by Goleman (1995) claimed that emotional intelligence is at least as important as IQ in predicting various forms of success and determine personal success as a social worker, student, teacher and manager. Rosenthal (1977) reports that the ability to identify people's emotion, i.e., empathy, contributes positively to one's professional and social success. Similarly, Bachman (1988) reports in a study that most effective leaders in the US Navy are warmer, more outgoing, emotionally expressive, dramatic and sociable. Thus, looking at the finding of these studies, it can be concluded that emotional intelligence and its competencies certainly augment people's performance in organisational lives especially voluntary work.

It does not seem that the EI measure can discriminate volunteers from non-volunteers. Thus, the importance of EI training for volunteers has not been realized from this study. The volunteers scored are significantly lower on intrinsic religious orientation than the scores for the non-volunteers. This suggests that intrinsic orientation does discriminate between volunteers and non-volunteers, but in the opposite direction found by Hanset, Vanderber, and Patterson (1995). These authors found a positive and significant correlation between intrinsic motivation and nonspontaneous (planned) helping behaviour. A similar analysis could have been done on the data in this study. However, the surprising, and questionable, pattern of response on the measure of frequency of participation in voluntary activities renders the analysis weak.

In another study, devout intrinsic religion is associated with antipathy towards value violators (Batson, Flyod, Meyer \& Winner, 1999). They are less likely to donate money to help people who violate religious values. Taken together, these seem to suggest that people with intrinsic religion will be more likely to participate in planned voluntary organizations that do not violate their religious values.

As for Extrinsic Personal orientation, the volunteers again scored significantly lower than the nonvolunteers. The volunteers reported less personal gain from embracing a religion. This result does not follow the findings of Hanset et al. (1995). The result, however, highlights the need for distinguishing the two dimensions of an extrinsic orientation (Gorsuch \& McPherson, 1989). The need is made clear here where different outcomes are revealed when Extrinsic orientation are divided into Extrinsic Personal and Extrinsic Social. Significant difference is observed for Extrinsic Personal orientation between volunteers and non-volunteers whereas the two groups scored similarly for the Extrinsic Social orientation. Therefore, this study lends support to measuring separate dimensions of the extrinsic orientation. 
The Extrinsic Social orientation score is not statistically different. Moreover, the volunteers' score (4.65) is close to the minimum possible score (3). It can be said that volunteers do not see religion as a vehicle for social gain. Having discussed the comparison, it should be noted that the actual scores for Extrinsic Personal and Intrinsic Social are high for both groups. The scores are closer to the maximum possible scores. Unfortunately, norm comparison cannot be made due to unreported actual mean score in the literature reviewed. Non-volunteers scored marginally higher on the emotional intelligence scale. Thus, both religious orientation and emotional intelligence are found to be lower in the volunteers.

The explanation for these findings should await further research, most suitably of a longitudinal nature. The EI scale itself appears to be suited for the Malaysian population, having sufficient internal consistency and producing comparable results with populations in a different country.

The suggestion that intrinsically oriented people tend to prefer non-spontaneous helping opportunity is not supported by this study. Intrinsic religious orientation was found to be higher in the non-volunteers. It was also found that extrinsic-personal orientation is lower among the volunteers. Therefore, the extrinsic orientation still needs to be considered when studying prosocial behaviour.

\section{Conclusion and Implication}

Emotional intelligence as a concept should not be discarded as a psychological variable that is important in understanding volunteerism. What researchers need to do is use an ability based measure of EI or other such measures that conceptualize EI as a cognitive ability, and not a trait. The importance of measuring extrinsic religious orientation separately for the personal and social dimensions is highlighted in this study. This separation can resolve some inconsistency in the data regarding the relationship of religious orientation and other psychological variables.

In conclusion, there is fertile ground for conducting research on volunteerism from the psychological perspective. More research needs to be done to understand why Malaysians participate and, just as important, not participate in planned voluntary activities. We need more volunteers to contribute to the vision of a caring society.

\section{References}

Baron, A.R., Byrne, D. \& Branscombe, N.R. (2006). Social psychology. $11^{\text {th }}$ ed. Pearson Education, Inc: Boston.

Bachman, W. (1988). Nice guys finish first: A SYMLOG analysis of US Naval Commands. In R.B.

Polley (Eds.), The SYMLOG practitioner: Application of small group research. New York: Praeger. Praeger.

Batson, C.D., Floyd, R.B., Meyer, J.M, \& Winner, A.L. (1999). "And who is my neighbour?:" Intrinsic religion as a source of universal compassion. Journal for the Scientific Study of Religion, 38(4), 445-457.

Batson, C.D., \& Schoenrade, P.A. (1991). Measuring religion as quest: 1) validity concerns. Journal for the Scientific Study of Religion, 30, 416-429.

Batson, C.D., \& Schoenrade, P.A. (1991). Measuring religion as quest: 1) reliability concerns. Journal for the Scientific Study of Religion, 30, 430-447.

Ciarrochi, J.V., Deane, F.P., \& Anderson, S. (2002). Emotional intelligence moderates the relationship between stress and mental health. Personality and Individual Differences, 32, 197-209.

Clary, E., Snyder, M., Ridge, R., Copeland, J., Stukas, A., Haugen, J., \& Miene, P. (1998). Understanding and assessing the motivations of volunteers: A functional approach. Journal of Personality and Social Psychology, 74, 1516 - 1530.

Donahue, M.J. (1895). Intrinsic and extrinsic religiousness: The empirical research. Journal for the Scientific Study of Religion, 24, 418-423. 
Egbert, N., \& Parrot, R. (2003). Empathy and social support for the terminally ill: Implications for recruiting and retaining hospice and hospital volunteers. Communication Studies, 54(1), 18-34.

Ellis, S.J. (1985). Research on volunteerism... what needs to be done. Journal of Voluntary Action Research, 14 (2-3), 11-14.

Eysenck, H.J., \& Eysenck, S.B.G. (1991). Manual of the Eysenck Personality Scales (EPS Adult). Hodder \& Stoughton: London.

Gorsuch, R.L., \& McPherson, S.E. (1989). Intrinsic/extrinsic measurement: I/E-Revised and singleitem scales. Journal for the Scientific Study of Religion, 28, 348-354.

Hansen, D.E., Vandenberg, B., \& Patterson, M.L. (1994). The effects of religious orientation on spontaneous and nonspontaneous helping behaviours. Personality and Individual Differences, 19(1), 101-104.

Liau, A.K., Liau, A.W.L., Teoh, G.B.S., \& Liau, M.T.L. (2003). The case for emotional literacy: The influence of emotional intelligence on problem behaviours in Malaysian secondary school students. Journal of Moral Education, 32, 51-66.

Lukka, P., \& Mocke, M. (2000). Faith, voluntary action and social policy: A review of research. The Journal of the Institute for Volunteering Research, 3(1). Retreived from www.ivr.org.uk/faith.htm, 5 July 2004.

Maltby, J. \& Lewis, C.A. (1997). The reliability and validity of a short scale of attitude towards Christianity among U.S.A., English, Republic of Ireland, and Northern Ireland adults. Personality and Individual Differences, 22, 649-654.

Maltby, J. (1999). Religious orientation and Eysenck's personality dimensions: The use of the amended religious orientation scale to examine the relationship between religiosity, psychoticism, neuroticism and extraversion. Personality and Individual Differences, 26, 79-84.

Maltby, J. (2002). The age universal I-E Scale-12 and orientation toward religion: Confirmatory factor analysis. The Journal of Psychology, 136, 555-560.

Maltby, J., \& Day, L. (1998). Amending a measure of the Quest Religious Orientation: Applicability of the scale's use among religious and non-religious persons. Personality and Individual Differences, 25, 517-522.

Maltby, J., \& Lewis, C.A. (1996). Measuring intrinsic and extrinsic orientation toward religion: Amendments for its use among religious and non-religious samples. Personality and Individual Differences, 21, 937-946.

Martha K. Wilson, M.K. \& Beville, B.A. (2003). Preemployment and volunteer screening: reducing the risk of child sexual abuse for social service agencies. Families in Society: The Journal of Contemporary Human Services, 84(2), 179-185.

Mayer, J.D., Caruso, D.R., \& Salovey, P. (2002). Relation of an ability measure of emotional intelligence to personality. Journal of Personality Assessment, 79(2), 306-320.

O'Connor Jr, R.M. \& Little, I.S. (2003). Revisiting the predictive validity of emotional intelligence: Self-report versus ability-based measures.

Okun, M.A., Shepard, S.A., \& Eisenberg, N. (2000). The relations of emotionality and regulation to dispositional empathy-related responding among volunteers-in-training. Personality and Individual Differences, 28, 367-382.

Omoto, A.M., \& Snyder, M.(1995). Sustained helping without obligation motivation, longevity of service, and perceived attitude change among AIDS volunteers. Journal of Personality and Social Psychology, 68(4), 671-686.

Park, J.Z., \& Smith, C. (2000). "To whom much has been given...": Religious capital and community voluntarism among churchgoing Protestants. Journal for the Scientific Study of Religion, 39, 272-286.

Penner, L.A., \& Finkelstein, M.A. (1998). Dispositional and structural determinants of volunteerism. Journal of Personality and Social Psychology, 74(2), 525-537.

Rosenthal, R. (1977). The PONS Test measuring sensitivity to nonverbal cues. In P. McReynolds (Eds.), Advances in nonverbal cues. In P. McReynolds (Eds.), Advances in psychological assessment. San Francisco, CA: Jossey - Bass.

Salovey.P \& Mayer.J.D (1990).Emotional intelligence.Imagination, Cognition and Personality,9, 259298.

Saroglou, V. (2002). Religion and the five factors of personality: A meta-analytic review. Personality and Individual Differences, 32, 15-25. 
Schutte, J.W., Hosch, H.M. (1996). Optimism, religiosity, and neuroticism: A cross-cultural study. Personality and Individual Differences, 20, 239-144.

Schutte, N.S., Malouff, J.M., Hall, L.E., Haggerty, D.J., Cooper, J.T., Golden, C.J., \& Dornheim, L. (1998). Development and validation of a measure of emotional intelligence. Personality and Individual Differences, 25, 167-177.

Schutte, N.S., Malouff, J.M., Simunek, M., \& Mckenley, J. (2002). Characteristics emotional intelligence and emotional well-being. Cognition and Emotion, 16, 769-785.

Trinidad, D.R. \& Johnson, C.A. (2002). The association between emotional intelligence and early adolescent tobacco and alcohol use. Personality and Individual Differences, 32, 95-105.

Trinidad, D.R., Unger, J.B., Chou, C., \& Johnson, C.A. (2004). The protective association of emotional intelligence with psychosocial smoking risk factors for adolescents. Personality and Individual Differences, 36, 945-954.

Uphdhyaya, S., \& Rahmatullah Khan, R.K. (1990). Malaysian adaptation of Eysenck Personality Questionnaire - some preliminary findings. In Othman, A.H., Abdul Rahman, W.R., (Eds.). Psychology and Socio-Economic Development, Collection of Working Papers 12. Penerbit UKM: Bangi.

Uslaner, E.M. (2002). Religion and civic engagement in Canada and the United States. Journal for the Scientific Study of Religion, 41, 239-254.

Wilde, A., \& Joseph, S. (1997). Religiosity and personality in a Moslem context. Personality and Individual Differences, 23, 899-900.

Wilson, J., \& Janoski, T. (1995). The contribution of religion to volunteer work. Sociology of Religion, $56(2), 137-152$. 